REFERENCES:

[1] Littlejohn GO, Tymms KE, Smith T, Griffiths HT. Using big data from realworld Australian rheumatology encounters to enhance clinical care and research. Clin Exp Rheum 2020:38(5): 874 -880.

Acknowledgements: The authors acknowledge the members of OPAL Rheumatology Ltd and their patients for providing clinical data for this study, and Software4Specialists Pty Ltd for providing the Audit4 platform.

Disclosure of Interests: Kathleen Tymms: None declared, Tegan Smith: None declared, Claire Deakin: None declared, Tim Freeman: None declared, David Hoffman: None declared, Dana Segelov: None declared, Hedley Griffiths Consultant of: AbbVie, Gilead, Novartis and Lilly., Sabina Ciciriello: None declared, Peter Youssef: None declared, David Mathers: None declared, Catherine OSullivan: None declared, Geoff Littlejohn Consultant of: Over the last 5 years Geoffrey Littlejohn has received educational grants and consulting fees from AbbVie, Bristol Myers Squibb, Eli Lilly, Gilead, Novartis, Pfizer, Janssen, Sandoz, Sanofi and Seqirus

DOI: 10.1136/annrheumdis-2021-eular.2253

\section{POS1462-HPR VALIDITY AND PSYCHOMETRIC CHARACTERISTICS OF THE PSORIATIC ARTHRITIS QUALITY OF LIFE (PSAQOL) QUESTIONNAIRE IN TURKISH POPULATION}

M. T. Duruöz ${ }^{1}$, K. Nas ${ }^{2}$, S. Acer Kasman ${ }^{1}$, E. Uzun ${ }^{3}$, H. H. Gezer ${ }^{1}{ }^{1}$ Marmara University, School of Medicine, Physical Medicine and Rehabilitation Department, Rheumatology Division, Istanbul, Turkey; ${ }^{2}$ Sakarya University School of Medicine, Division of Rheumatology and Immunology, Department of Physical Medicine and Rehabilitation, Sakarya, Turkey; ${ }^{3}$ Sakarya University School of Medicine, Department of Physical Medicine and Rehabilitation, Sakarya, Turkey

Background: Psoriatic Arthritis Quality of Life (PsAQoL) questionnaire was developed to measure quality of life $(\mathrm{QoL})$ in patients with psoriatic arthritis (PsA) (1).

Objectives: The aim of the study was to assess validity and psychometric properties of the PSAQoL questionnaire.

Methods: The translation-back translation method by a bilingual panel was used to translate the original PsAQoL into Turkish (2). Face and content validities were evaluated via cognitive debriefing interviews with 10 PsA patients. Then, patients with PsA according to CASPAR criteria were recruited to assess feasibility, missing data, floor and ceiling effect, reliability, and construct validity. Reliability was assessed by internal consistency. Construct validity was investigated by convergent and divergent validity by assessing the PsAQoL's relations with QoL and non-QoL parameters. For this purpose, demographics, clinical characteristics (shown in Table 1), survey data including PSAQoL, Short form 36, visual analog scales for pain and fatigue, Health Assessment Questionnaire, and Hospital Anxiety and Depression Scale results were recorded.

Results: One hundred and sixty-two patients were recruited and 74 of them had axial PsA. Cognitive debriefing showed the Turkish version of PsAQoL to be clear, understandable, and relevant. It was easy to complete and calculate, with the 3 minutes and 20 seconds, respectively. The Cronbach's alpha coefficient for internal consistency was 0.930 . The questionnaire presented no floor or ceiling

Table 1. Spearman's correlation coefficients of PsAQoL with the other parameters for construct validity

\begin{tabular}{|c|c|c|c|c|c|}
\hline \multicolumn{3}{|l|}{ Convergent } & \multicolumn{3}{|c|}{ Divergent } \\
\hline SF-36 subscales & Rho & Clinical Parameters & Rho & Surveys & Rho \\
\hline Physical component & $-0.744^{\star *}$ & Age & 0.150 & BASDAI (n:74) & $0.355^{\star \star}$ \\
\hline Mental component & $-0.731^{* *}$ & Disease duration & 0.014 & VAS Pain & $0.408^{\star \star}$ \\
\hline Physical functioning & $-0.629^{\star *}$ & Tender joint count & $0.262^{* *}$ & VAS Fatigue & $0.447^{\star \star}$ \\
\hline Physical role limitations & $-0.640^{\star \star}$ & Swollen joint count & $0.170^{\star}$ & $\mathrm{HAQ}$ & $0.533^{\star \star}$ \\
\hline Emotional role limitations & $-0.576^{\star *}$ & MASES & 0.152 & HADS Anxiety & $0.535^{\star \star}$ \\
\hline Vitality & $-0.657^{* *}$ & PASI & -0.032 & HADS Depression & $0.517^{\star \star}$ \\
\hline Emotional well-being & $-0.590^{* *}$ & DAPSA & $0.409^{\star \star}$ & & \\
\hline Social functioning & $-0.591^{\star *}$ & DAS28 & $0.322^{\star *}$ & & \\
\hline Pain & $-0.535^{\star *}$ & BASMI (n: 61) & 0.032 & & \\
\hline General health & $-0.536^{\star *}$ & & & & \\
\hline
\end{tabular}

${ }^{* *} p<0.001,{ }^{*} p:$ 0.001-0.049.PSAQoL: Psoriatic Arthritis Quality of Life, SF-36: Short Form 36, MASES: Maastricht Ankylosing Spondylitis Enthesitis Score, PASI: Psoriasis Area Severity Index, DAPSA: Disease Activity in PSoriatic Arthritis, DAS28: Disease Activity Score 28, BASMI: Bath Ankylosing Spondylitis Metrology Index, BASDAI: Bath Ankylosing Spondylitis Disease Activity Index, VAS: Visual analog scale, HAQ: Health Assessment Questionnaire, HADS: Hospital Anxiety and Depression Scale. effect ( $<15 \%$ for both) and no missing data. PsAQoL showed good correlations with the QoL scales indicating its convergent validity and moderate to non-significant correlations with the non-QoL parameters supporting its divergent validity (Table 1).

Conclusion: The Turkish version of the PsAQoL is a valid and disease-specific instrument with good psychometric characteristics to assess PsA-specific QoL.

\section{REFERENCES:}

[1] McKenna SP, Doward LC, Whalley D, Tennant A, Emery P, Veale DJ. Development of the PSAQoL: a quality of life instrument specific to psoriatic arthritis. Ann Rheum Dis. 2004;63(2):162-169.

[2] Beaton DE, Bombardier C, Guillemin F, Ferraz MB. Guidelines for the process of cross-cultural adaptation of self-report measures. Spine (Phila Pa 1976). 2000;25(24):3186-3191.

Disclosure of Interests: None declared

DOI: 10.1136/annrheumdis-2021-eular.3311

\section{POS1463-HPR IMPACT OF COVID-19 PANDEMIC ON DISEASE ACTIVITY AND EMOTIONAL WELL-BEING AMONG RHEUMATOID ARTHRITIS PATIENTS: A TELEMEDICINE STUDY}

B. Lucchino $^{1}$, C. Iannuccelli ${ }^{1}$, C. Gioia ${ }^{1}$, G. Dolcini ${ }^{1}$, M. DI Franco ${ }^{1} .{ }^{1}$ Sapienza University of Rome, Dipartimento di Scienze Cliniche Internistiche,

Anestesiologiche e Cardiovascolari, Rome, Italy

Background: By the beginning of March 2020, the pandemic of the novel coronavirus disease (COVID-19) imposed severe lockdown measures opposing the viral spread, limiting non-COVID patients' access to hospitals Previous reports suggest that Rheumatoid Arthritis (RA) patients may experience a worsening of self-reported disease activity following natural disasters. Moreover, RA patients are at increased risk of mood disorders, such as depression and anxiety. An increase of depressive symptoms, anxiety and suicidal rate has been recently reported as result of the lockdown in response to COVID-19.

Objectives: Aims of this study were to investigate the impact of the lockdown measures on disease activity and emotional well-being among patients affected by RA, through a telemedicine approach.

Methods: Patients followed in the "Early Arthritis Clinic" of our hospital were invited to participate to an online survey. They were asked also to invite their best friend (BF), matched for age and sex, to participate the survey, as control group. Moreover, clinical records from the same "Early Arthritis Clinic" cohort were used as pre-pandemic group. The online survey included demographic questions and, for RA patients, the evaluation of perceived pain (P-VAS) and disease activity (DA-VAS) on a scale of 1-10 as well as Rheumatoid Arthritis Disease Activity Index-5 (RADAI-5), a validated self-reported disease activity measure. Both RA patients and BF responded also to validated, psychometric scales for stress vulnerability (Stress Vulnerability Scale-SVS), resilience (Resilience Scale-RS), depression (Zung's depression questionnaire-Zung-D) and anxiety (Zung's anxiety questionnaire-Zung-A) evaluation.

Results: The cohort was composed by 76 RA patients who answered the survey, 32 BF and 170 RA patients from historical cohort. There were no differ ences in demographic characteristics, SVS, RS, Zung-D and Zung-A between RA patients and BF. RADAl-5 correlated positively with SVS $(r=0,29 ; p=0,01)$, P-VAS $(r=0,8 ; p<0,0001)$ and DA-VAS $(r=0,8 ; p<0,0001)$ and negatively with $R S$ $(r=-0,23 ; p=0,04)$. Patients with higher disease activity showed higher classes of Zung-D $(p=0,03)$ and SVS $(p=0,006)$, and lower classes of $R S(p=0,001)$. P-VAS was the only significant predictor of $\operatorname{RADAl}-5(\beta=0,83 ; \mathrm{Cl}=0,53-0,76 ; \mathrm{p}<0,001)$, and the concordance between RADAI-5, P-VAS and DA-VAS was high $(K=0,94 ; p<0,001)$. Compared with the historical cohort, RA patients involved in the survey showed higher frequencies of moderate and elevated disease activity classes $(p<0,001$; Figure 1$)$ despite there were no differences in P-VAS and DA-VAS.

Conclusion: These results suggest that lockdown did not affect differently emotional well-being of RA patients compared to healthy subjects. RA patients with elevated disease activity report higher stress and depressive symptoms, and SVS and RS may be useful to identify patients at higher risk. The higher self-reported disease activity measured through RADAI- 5 may be the result of an overestimation of disease severity by patients, which depends mostly from pain. This should be considered in the assessment of disease activity through telemedicine. 